\title{
Las leyes por la brevedad y orden de los pleytos, de 1499. Reforma procesal de la Reina Isabel
}

\author{
José Manuel Pérez-Prendes Muñoz-Arraco
}

Arbor CLXXVIII, 701 (Mayo 2004), 87-106 pp.

\section{Presupuestos}

En todo tiempo se han acercado las gentes a los juicios con recelo y curiosidad. Son el espacio donde sentimientos e intereses muy particulares, que de buena gana se celarían a la percepción de la mayoría de las personas, quedan necesariamente publicados en una escenificación decisoria ante sujetos ajenos. Las fuentes medievales que hablan de «escodriñamiento» para referirse a algunos de esos procesos, acertaron de lleno en el lado psicológico de quienes los protagonizan, que así se sienten, hurgados como trapos, en el originario sentido latino de scrutari, ante quienes los miran y oyen para juzgarlos o para oir y ver cómo les juzgan.

Ese desvalimiento, casi humillación, refuerza el prestigio social adquirido por los poseedores de la plena facultad de juzgar con fuerza final. Los dioses en todo tiempo, los pontífices y los reyes en el medievo, adquirieron esa inefable categoría de supremos jueces y la referencia al reyjuez, constituyó, como bien escribió Antonio Marongiu, un rasgo típico de las monarquías posromanas.

Sin duda a Isabel de Trastámara y Avís, mujer religiosa en cuya testamentaría encontró varias Biblias vulgatas don Antonio de la Torre, no le era desconocido el famoso pasaje del Libro de los proverbios que puede traducirse así, teniendo en cuenta el texto que ella leería:

«Los sobornos de los hombres les allanan el camino y les abren vías hacia los príncipes. Justo parece el primero que acusa en su pro, pero llega su antagonista y rechaza con precisión lo que aquel dijo. Las contradicciones dificultan la solución. Y 
también hay que sentenciar entre poderosos, si uno ayuda a su igual, son como plaza fuerte y los juicios quedan ya casi como los cerrojos de una ciudad» (18; 16-19).

\section{Una demanda social}

Le tendría que resultar casi imposible a la reina sustraerse, leyendo esas frases, al recuerdo de las constantes quejas de las Cortes de cualesquiera reinos acerca de los juicios. Bien claro le habían dicho los procuradores a ella, como a otros reyes antes y desde hacía mucho que esos procesos, además de largos, venían estorbados por multitud de alegaciones jurídicas, todas en apariencia atendibles. Denunciaban que casi siempre sufrían la amenaza de ser perturbados en su desarrollo por presiones sociales. Lamentaban que estuviesen determinados muchas veces por la insolente impunidad de los poderosos, coligados en su provecho común. Advertían que el fantasma de los cohechos, nunca dejaba de materializarse con demasiada nitidez y desvergonzada reiteración. Y concluían subrayando que, con demasiada frecuencia, se generaban por culpa de todo eso, decisiones y sentencias injustas, solidificadas en su fuerza e influjos luego de dictadas, pese a lo necesario de romper precedentes que nunca habrían debido establecerse. Ese resúmen no es una exageración. Quizá no haya otro tema en la historia de los alegatos planteados a los soberanos por las Cortes, tan agudo e insistente como las quejas por la administración de justicia.

\section{Las intenciones de Isabel}

Que la reina Isabel quiso corregir ese estado de cosas parece bastante claro. Las investigaciones acerca de su obra de gobierno coinciden, con razón, en resaltar la importancia que tuvieron varias iniciativas esenciales en esa dirección. Una, la revisión prolongada que forman la promulgación y actualización de las Ordenanzas de la Real Audiencia y Chancillería de Valladolid desde 1485 hasta 1489, y la creación en 1494 de la nueva y paralela sede jurisdiccional que acabaría recalando en Granada; esfuerzos a los que se debe reconocer un importante papel en la gestación de la magistratura moderna. Otra, había sido en 1476, la generalización potenciada de las viejas Hermandades. Sobre esas medidas instrumentales estaba la voluntad orientada a desterrar las corrupciones forenses, vieja enfermedad que no habían conseguido curar las leyes desde los tiempos del ostrogodo Teudis. De esta constante intención es prue- 
Las leyes por la brevedad y orden de los pleytos...

ba la actitud de los jueces. Según el cronista Pulgar «avían gran temor a la Reyna», expresión que no es una frase aislada, sino que encierra coherencia con los testimonios dados por otras fuentes.

He ahí, pues, señalados dos de los objetivos regios. Un aparato institucional bien calibrado y capaz de cumplir sus tareas. Unos jueces honestos. Sin embargo, si ambas cosas eran necesarias, no eran suficientes. Es verdad que con ellas quedaba orientado por un buen camino señalar quienes debían juzgar y como debían huir de cometer delitos en el ejercicio de esa función.

Pero era necesario poner mano simultáneamente en como debían sustanciarse los procesos. Los juicios son como la sangre que corre por aquellas venas institucionales y se vigila y dosifica por estos artífices juzgadores. Si se deseaba evitar la melancólica visión bíblica; la desagradable necesidad de obligar de vez en cuando a dimitir a jueces mediatizados, como los de Valladolid en 14911, y la aspereza reiterativa de las quejas de las Cortes, era preciso hacer intervenir mucho más a la ley en el desenvolvimiento de los juicios mismos.

\section{¿Qué significa una reforma procesal?}

Con ser las Leyes de 1499 para la reforma de tales juicios, que aquí se van a comentar brevemente, una de las piezas más importantes de la legislación de los Católicos, apenas han recibido consideración alguna por parte de los especialistas de su reinado. Pero ese es un hecho que correlaciona con otro. Las reformas procesales de cualquier época han sido las que menos atención han recibido de los investigadores, salvo, claro está, los muy especializados.

Podría haber mitigado ese desinterés el hecho de que en una sociedad estamental, como era la española del siglo XV, las leyes que regulan los juicios constituyen unas de las escasísimas posibilidades de nivelación relativa de las diferencias sociales.

Cuando en la misma época se observan las tenazas de la estamentalidad, descoyuntando sin reparo obligaciones vertebradoras del Estado, como ocurre con la tributaria, se comprende bien el papel de integración social que poseen de suyo las normas procesales, mucho mayor desde luego que las destinadas a otras dimensiones de la vida jurídica de los súbditos. 
Sin incurrir en la demasía de afirmar que los pasos que se comentarán en este escrito dieron lugar una igualdad de los súbditos ante el Derecho, algo que ciertamente no ocurrió, no se debe ocultar tampoco el valor intrínseco que poseyó en esa dirección el tipo de actuaciones que, como la reforma procesal, dotaba de sentido político último a la casuística jurídica por donde alboreaba el Estado moderno.

Absurdo sería pretender una falsa potenciación de la imagen isabelina adjudicándole ideas de hoy que no podían estar en sus horizontes mentales. Comprender cómo un proceso justo es buena forma de aminorar las desigualdades de los súbditos, si es rasgo atribuible a Isabel, y no es poco. Baste con eso.

\section{Los obstáculos frente al intento}

Pero la tarea de reformar el proceso era bastante más difícil que la de crear instituciones jurisdiccionales modernizadas para su tiempo, o la de perseguir penalmente a los abundantísimos jueces corruptos y a los salteadores de caminos. Una estructura institucional eficaz es accesible mediante un inventario de necesidades materiales, un diseño de las soluciones mecánicas posibles y unos medios que satisfagan esas necesidades. Con una vigilancia atenta de sus decisiones, puede conseguirse mucho en la lucha por hacer predominar entre los jueces, a aquellos que sean honrados. Aún a costa de injusticias parciales se podía, con la Santa Hermandad, asegurar una cierta paz social, etc.

Pero una reforma procesal es probablemente la más difícil de las reestructuraciones legales concebibles. La razón por la que cualquier reforma procesal se hace tan difícil, reside en que, para ser digna de tal nombre, requiere al menos un cuádruple bagaje.

Un conocimiento exhaustivo de todas las áreas del Derecho, pues todas circulan por los juicios y no pueden, por su propia esencia, pasar de la misma manera.

Una experiencia sobre cómo son y cómo actúan las pautas de comportamiento y de necesidades instaladas en la sociedad para la que se legisla, pues de esas rutinas vendrán las dosis de resistencia o de aceptación que pueden hacer flotar o pueden hundir el intento transformador.

Una voluntad real de lograr una justicia honesta y no sólo de aparentarla con leyes efectistas en un primer momento, pero inmaduras o ineficaces después. 
Por fin, hay que manejar con soltura la técnica jurídica más extremada, a fin de dibujar cómo debe pleitearse, sorteando los escollos de amenazas constantes a la igualdad de las partes, a la seguridad de las pruebas y a la fundamentación y eficacia de las sentencias.

Hay que reconocer que el empeño no es, nunca en absoluto, fácil en sí mismo. Eso en ningún tiempo. Pero podemos preguntarnos si hubo algún momento especialmente oportuno en el reinado de Isabel para tomar la decisión, necesaria pero grave, de reformar el proceso.

La respuesta es negativa y lo es, no tanto porque se viviese un tiempo en el que se había hecho tradición social el ensoberbecimiento de quienes podían influir de hecho sobre las decisiones de los jueces. Siendo eso muy cierto representaban todavía mayor dificultad dos protagonistas de lo procesal que alcanzaban entonces su máximo apogeo, escapando a las posibilidades legislativas de cualquier monarca. El ius commune y la jurisdicción eclesiástica. La decisión, pues, de acometer la reforma revela un voluntarismo político extraordinariamente fuerte, que no debe minusvalorarse. Veamos brevemente cuales eran esos obstáculos

\section{De cómo cierto uso de la ciencia de calidad puede generar daños sociales}

Lo que conocemos como ius commune, dominante en los reinos de Isabel y Fernando, es la máxima cota de la cultura jurídica europea a lo largo de la Historia. Se integraba ese Derecho, no solo por las inmensas moles legales del Corpus iuris canonici y del Corpus iuris ciuilis, sino también por decenas de miles de opiniones lanzadas sobre todas las posibles materias del Derecho, aún las más minúsculas, por los glosadores y comentaristas de tal océano legislativo. Se había formado así una intrincada «casa del tesoro», donde se podían buscar las más variadas soluciones $\mathrm{y}$, además, bien distintas, para cualquier duda por rebuscada que fuese.

Esa multiplicidad, que era el orgullo intelectual de las Universidades, se transformaba en una plaga de dudas y debates inacabables, cuando todas las partículas de semejante repertorio eran implantadas simultáneamente en los alegatos judiciales con la fuerza que les daba el prestigio científico de su origen. Sobrecoge todavía hoy profundizar un poco en lo que los propios Reyes Católicos describieron escuetamente como:

«la diversidad e ambiguidad de opiniones de doctores, que los juezes e sus asesores fallan para la determinación de las causas». 
Era lógico que se quisiese curar la inseguridad social engendrada al sentenciar unas causas hoy apoyándose en algunas de esas opiniones, y que mañana, otras análogas, recibiesen una solución contradictoria con la ya dada, por haberse apoyado cada vez los letrados y el juez en criterios de diversos autores. Pero por otro lado resultaba imprescindible asumir que, obviar o despreciar esa catarata de leyes y doctrinas, iba radicalmente en contra de lo que marcaban la modernidad y el progreso de la vida jurídica. Debemos entender que esa convicción era absolutamente unánime.

Es necesario añadir que, siendo grave ese problema de las sentencias diversas en causas iguales, la inseguridad no se acababa ahí ni mucho menos. Al menos con sentencias hubiesen concluido los pleitos, aunque fuesen decididos de formas distintas cada uno de los que eran similares. Casi peor era que no concluían, sino después de estertores agónicos y prolongados de una dialéctica agotadora, insufrible y antieconómica. En realidad, las inagotables torrenteras conceptuales de las leyes canónico-romanas y de sus glosadores y comentaristas, alcanzaron el esplendor de sus aguas suministrando argumentos para las llamadas excepciones procesales. Eran estas, argumentos destinados a que todo litigante pudiese esquivar la pretensión principal de la parte contraria que motivaba el pleito, sin entrar a discutir el fondo de esa cuestión.

Las había principalmente de dos clases; perentorias para negar la capacidad jurisdiccional y dilatorias, para retrasar la sentencia. Así, podía alegarse por ejemplo, que se había acudido ante un juez carente de competencias para decidir la cuestión discutida; o que estaba excomulgado y no podía conocer de proceso alguno; o que ya se había realizado lo que una parte reclamaba; o que ésta se había comprometido a no reclamar jamás lo que ahora exigía; o reconvenirla por acusar a otro de actos que ella misma había cometido...Se trataba en definitiva, ya de eludir el pleito, ya de dilatarlo lo más posible, si se vislumbraba que la sentencia podía ser contraria. La casuística alegable con esos fines era el reino de los doctores legum, cuya doctrina inundaba la práctica jurídica.

Fruto de su presencia hegemónica resultó ser que en las Cortes de Briviesca de 1387 se rompiese la tradición visigótica que permitía el estudio del Derecho extranjero pero prohibía su aplicación. Dado ese paso, las leyes y doctrinas canónico-romanas habían inundado el ámbito forense peninsular.

Sin embargo los reyes y las gentes de sus pueblos percibían que; pese tanto orgullo por la multiplicidad y riqueza de ideas de los autores y le- 
Las leyes por la brevedad y orden de los pleytos...

yes que creaban ese ius commune recién importado; pese a que era sumamente fecundo en lo científico, no dejaba de resultar un lastre pesado y desorientador en la vida procesal que, cada pretensión de los litigantes y cada opción de los jueces, pudiese estar simultáneamente combatida y apoyada por decenas de opiniones y todas ellas tuviesen derecho a ser esgrimidas en igualdad de efectos. Por eso, en 1427, el padre de la Católica, Juan II, tendría que mandar salomónicamente a los abogados no:

«sean osados de allegar...e mostrar...en..manera alguna...nin dicho nin autoridad nin glosa de cualquier doctor nin doctores de los que han seido fasta aquí, después de Juan Andrés e Bartulo, nin otrosí de los que fueren de aquí en adelante; nin los juezes los reciban, nin judguen por ellos, nin por alguno dellos».

Aunque se hacía así un coto cerrado para los alegatos y sentencias procesales que se apoyasen en la doctrina de canonistas y romanistas procedentes del ámbito italiano, al fijar un límite, bastante tosco por cierto, con los que hubiesen escrito hasta mediados del siglo XIV (el canonista Giovanni d'Andrea muere en 1348 y el enciclopédico Bartolo da Sassoferrato, en 1357) lo cierto es que ahí se nos reconoce por el legislador que la vertebración de la vida jurídica española venía ya referida a la forma que adoptó ciencia del ius commune bajo el llamado mos italicus o bartolismo. Lo sería desde entonces y para siempre. «Nadie es jurista, si no es bartolista» rezaba un proverbio indiscutido en los ámbitos forenses.

Contaba Juan de Mena con dieciséis años, cuando se promulgó esa Pragmática de Juan II. Por eso si (como aceptan la mayoría de los estudiosos y críticos de la Literatura española) le pertenece el Decir sobre la Justicia e pleytos, e de la grant banidad deste mundo (publicado por José María Octavio de Toledo en 1876) debe ser entendido ese poema como un testimonio, posterior a 1427, de la aplicación de aquella ley, así como del sentimiento generalizado de desmoralización que acogía la presencia de tantas opiniones en la vida judicial.

De lo primero, es decir del uso amplísimo de alegaciones que la ley permitía, es muestra el hecho de que los autores y leyes que menciona el poeta cordobés en calidad de ejemplos del desenfreno de alegaciones procesales, son efectivamente anteriores a los que Juan II señaló como límite.

«viene el pleyto a disputación

ally es, bartolo e chino digesto

Juan Andrés e baldo, enrrique do son

mas opiniones que unas en cesto 
alli non es azo nin decretal

nin es ruberto nin la clementina»

Veamos la citas. Se trata de: «chino», es decir Cino Sighibuldi da Pistoia, romanista y poeta muerto en 1336 . De «enrrique», que debe ser con muchísima posibilidad Enrico da Susa, canonista y cardenal de Ostia (de ahí el sobrenombre de «Ostiense») y Velletri, fallecido en 1271 y no el romanista Enrico di Baila, personaje mucho más oscuro. De «azo», el archiconocido romanista Azzone, muerto en 1220. De «ruberto» que, mejor que el escasamente conocido canonista de la mitad del siglo XV Robertus Finingham (quien además cae un poco justo para venir citado por Mena) podría ser Uberto da Bobbio, mejor que Uberto de Orto, feudista que no viene aquí demasiado a cuento, pese a su fama como tal. Considero que, aún admitiendo un error (quizás del copista del poema) sería más lógico pensar en Alberico (Alberto) da Rosate, desaparecido en 1354 y a quien se conoce como «el práctico» por excelencia. Por lo demás, el resto de las citas que hace el poeta de los ya citados aquí, Bartolo y Juan Andrés, no precisan de mayores aclaraciones que las hechas. De Baldo, a quien también se refiere Juan de Mena, hablaremos más abajo.

Y no son solo autores, sino también leyes. Hace mención el cordobés y todo el mundo sabe qué cosa son las obras que cita, a los Digestos justinianeos y a las Decretales, de las que circulaban diversas colecciones, complementando a la principal promulgada por Gregorio IX. No omite una referencia a la «clementina», como se conocía la decretal Saepe contingit, de Clemente V (1305-1314) recogida en la colección de Constituciones de ese Papa, 5, 11, 2, que tanta importancia tuvo como modeladora de la simplificación de los procesos canónicos.

La actitud del poeta no puede ser más clara respecto del segundo factor arriba indicado, esto es, el agobio y la frustración social venida de que se exprimiese literalmente, por el oportunismo de clientes y gentes del foro, cuanta maniobra más o menos falaz se podía albergar bajo las opiniones contrapuestas de esa serie de autoridades. Acoge la condena de esas prácticas de la forma más explicita posible, señalando con acritud el resultado al que conducían tales demasías en la vida procesal. Tras informar que:

«et en cuarenta años no es acabado

un solo pleyto, mirad si es tormento» 
Las leyes por la brevedad y orden de los pleytos...

No se cansa de reiterar que tamaña cosa sucede gracias las constantes alegaciones de aquellos autores y leyes, pues en los procesos se esgrimen «más opiniones que uvas en cesto», y por culpa de eso:
«dan infinitos entendimientos
con entendimiento del todo turbado
socauan los çentros e los firmamientos
razones sufísticas e malas fundando
e jamas non vienen y determinando
que donde ay tantas dubdas e opiniones
non ay quien de, determinaçiones
e alos que esperan, conuien de yr llorando».

El remedio sería que el monarca hiciese frente con dureza a los juristas, tachados en conjunto y sin matices de cínicos y ladrones. Por mucho que exagerase Juan de Mena, otras fuentes y no escasas coinciden al final en un diagnóstico muy parecido:

«pues de abogados e de procuradores e aun de otras cient mill burlerias et de escribanos et recaudadores que roban el Reno por estrañas vías yo vi tantos en todos mis días e tanto padece este Regno cuytado que es maravilla, non seer asolado si el señor Rey non quiebra esta lias»

\section{De la Iglesia como creadora y guardiana del proceso}

Junto al obstáculo del ius commune estaba el de la juridiscción eclesiástica. Hoy no se suele percibir con claridad, cuando se habla de ius commune y se menciona la mixtura canónico-romana que principalmente lo integra, que esa masa teórico-legal solo podía ser aplicada en los juicios por la Iglesia y por los reinos cristianos. Las magistraturas de Roma ya no existían, y por tanto la autoridad de los criterios romanos solo podía venir de su calidad intrínseca, no de que los pretores o los emperadores, como hacían siglos antes, juzgasen aplicando unas leyes que se renovaban de continuo. El prestigio de las normas canónicas venía también de su calidad, pero no puede despreciar el infinito protagonismo adquirido además por los Papas y por los tribunales eclesiásticos, que trasfor- 
maban la doctrina canónico-romana en leyes y sentencias, es decir en las más típicas formas de creación del Derecho.

Por eso los Reyes Católicos, no se propusieron cambiar el procedimiento. La verdad es que ni siquiera podían pensarlo. El proceso aplicado por el sistema jurídico del ius commune, en el que participaban todos los reinos de Europa centro-occidental venia moldeado esencialmente por la Iglesia y se aplicaba por su jurisdicción en las amplísimas áreas del Derecho aplicable a los particulares, a cuyo conjunto llamamos Derecho privado, especialmente en el ámbito de las relaciones familiares, dada la sacramentalidad del matrimonio, que se extendía hasta sus últimas consecuencias, como la filiación, la capacidad hereditaria, etc. No hubiese sido, ni política ni científicamente posible, romper ese modelo procesal. De modo que en España, como en todas partes, los Estados aprovechaban la veteranía eclesiástica en el juzgar, para seguir la estela de sus pasos reproduciéndolos en los tribunales seculares.

\section{Vías, instrumento y criterios para la reforma}

Así pues, para cualquier reforma, solo cabía operar dentro de dos grandes estrechamientos de posibilidades. No se podía ir contra la novedad progresista que significaba la ciencia jurídica del ius commune, cada vez más florecida. No era posible salir del proceso diseñado por la jurisdicción eclesiástica. Con todos los inconvenientes que se engendrasen por ambas condicionantes, lo que no se podía discutir es la superioridad de una y otra sobre los arcaicos usos normativos medievales y sobre los juicios ordálicos de los alcaldes medievales erizados de irracionalidad, inseguridad e intuición. No era racional concebir ninguna reforma, que rompiese aquellos dos quicios. En tal ambiente se vio forzada la reina Isabel a acometer la reforma procesal, última y decisiva fase de acción que requería su esfuerzo por sanear la administración de justicia.

El instrumento empleado fue un conjunto de algo más de cuarenta Ordenanzas procesales, promulgado por una Pragmática de 1499 en la villa de Madrid, grupo que se imprimió bajo el título de Leyes hechas por los muy altos e muy poderosos principes e señores el rey don Fernando e la reyna doña Isabel nuestros soberanos señores por la brevedad e orden de los pleytos fechas enla villa de Madrid año del Señor de mil.cccc.xc.ix.

Forman uno de los más significativos incunables jurídicos españoles (estudiado como tal por José Moreno Casado en 1955), impreso por Fernando de Jaén, a quien la Real Audiencia y Chancillería de Valladolid 
otorgó privilegio de edición y venta por dos años y reimpreso en Granada en 1973 y 1993.

Más importante que esos datos es señalar que se trata del texto legal más influyente de nuestra historia jurídica en esa materia, como lo prueba la larga vida que habría de alcanzar. Sus preceptos, casi literalmente conservados en vigor en su distribución y contenidos iniciales a través de la Recopilación de 1567 (libro 4, título 2), y de la Novísima Recopilación de 1805 (libro 11, y diversas leyes de los títulos, 2, 3, 4, 5, 6, 7, 9, 10, 11, $17,13,20,21$, y 22 , en que se reordena su estructuración originaria) alcanzarían en buena parte hasta el siglo XIX, recogiéndose tanto en la Instrucción del procedimiento civil con respecto a jurisdicción ordinaria, promulgado por la segunda de las Isabeles reinas de España en 1853, como en la primera Ley de enjuiciamiento civil, de 1855.

Fueron el fruto de una Junta «ad hoc», convocada en la Corte e integrada por obispos, consejeros, jueces y «letrados scientificos e espertos en las causas e negocios». No debe dejar de valorarse la presencia de los dos tipos de juristas citados, unos investigadores y otros abogados, junto a los representantes de la gobernación, la administración de justicia y la Iglesia. Ya solo esa cuidada composición mostraría la voluntad de emplear todos los medios necesarios para lograr soluciones acordadas, razonables y eficaces.

La lectura de estas Ordenanzas hace muy difícil resistirse a pensar que el espíritu de la Saepe contingit, promulgada en 1307 por el Pontífice Clemente V en Avignon, en 1307 (la «clementina» que hemos oido mencionar a Juan de Mena) no haya sido la guía que pretendieron seguir sus redactores.

Se les había dicho a los jueces en ella que amputasen las dilaciones en la causa, haciendo el proceso todo lo breve que pudiesen, rechazando las excepciones apelatorias, dilatorias y frustratorias, refrenando la multitud superflua de testigos y los abusos de las partes y sus abogados y procuradores, pero todo ello sin que esa abreviación supusiese la eliminación de las pruebas necesarias y las defensas legítimas. Se encarecían también la fijeza y brevedad en los plazos, la seguridad en lo cierto de las manifestaciones de los litigantes y la rapidez, publicidad y ejecución de las sentencias.

Ciertamente que así se dibujaba un proceso sumario «simple y de plano, sin estrépito ni figura de juicio» y en cambio las Leyes de Madrid lo que buscan es la revisión general del proceso típico en todas sus instan- 
cias, pero no parece que pueda discutirse mucho que su intención es trasladar a cada una de ellas ese sentido general que respira la Constitución clementina, sobre todo teniendo en cuenta que si miramos a los principales precedentes hispanos de las Leyes isabelinas, encontramos que, si podemos encontrar definiciones científicas de conceptos procesales en las Flores de las leyes del maestro Jacobo, o en el Doctrinal; y normativas procesales en Siete Partidas, Fuero Real, Ordenamiento de Alcalá de 1348, y leyes regias diversas, dadas en Cortes o fuera de ellas (cuya sistematización intentó Alonso Díaz de Montalvo en sus Ordenanzas Reales de Castilla), en ninguno de tales textos se encuentra una regulación con pretensiones tan amplias de totalidad y de saneamiento procesal, trazadas a partir de un conocimiento seguro de la realidad y de sus condicionantes, como la que nos ofrecen estas Leyes madrileñas de 1499.

Por último, quisiera apuntar que, tanto por ese carácter y sentido general, como por la forma de redacción desarrollada en la promulgación, que sigue a la Ordenanza 44, sería muy discutible pensar que no existía en la mente de los monarcas la voluntad de que se utilizasen como guía procesal en todos sus reinos.

\section{Los principios básicos de la reforma}

Sea como fuere lo cierto es que dadas las coordenadas en que se movían, la fórmula que podían aplicar los comisionados era solo una, tomar el hilo del desarrollo procesal canónico-romano en abstracto y desde sus comienzos, para ir marcando los abusos que debían evitarse. El texto de las Leyes de Madrid, se convierte así en una visión crítica del desarrollo del proceso en todas sus instancias, vistas a la luz de esa vocación de simplicidad que se respira en la Saepe contingit.

Por eso lo primero que destaca en ellas son sus intenciones de operatividad, de realismo y de universalidad. Quiero decir con eso que se propusieron el uso racionalizado de una ciencia de la que no podía prescindir; el saneamiento en el uso de las armas de que disponían los jueces, a los que se coloca claramente ante su responsabilidad como directores-decisores del proceso. Por último, señalo la pretensión de depurar entero el edificio procesal, en la totalidad de sus elementos.

La primera intención, la operatividad, es desde luego la más conocida. Reside en la forma de revisar la decisión de Juan II, que limitaba del modo que se ha visto ya aquí antes la alegación de opiniones de juristas. 
En las Leyes de 1499 quedó sustituida la fórmula aplicada en 1427 por un sistema que reemplazaba la referencia cronológica por otra inspirada en la competencia y en la calidad:

\footnotetext{
«Otrosí muchas vezes acaesce que enla decisión delas causas ha hauido e hay mucha confusion por la diversidad delas opiniones delos doctores que escribieron, mandamos que en materia canonica se prefiera la opinión de Juan Andrés e en defecto dela opinión de Juan Andrés se sigua la opinión del abad de Sicilia: e en materia legal se prefiera la opinión del Bartholo e en defeto della se sigua la opinión del Baldo» Ordenanza 37.
}

Como se ve, junto a los dos especialistas mencionados por Juan II se añadieron Niccolò de' Tedeschi, llamado el Abad de Sicilia, o Panormitano, o Siciliano, o «moderno» (muerto en 1453) y Baldo de los Ubaldis, discípulo de Bartolo y muerto en 1400.

Tenían por misión suplir las lagunas que pudiesen darse en la doctrina de los dos ya citados por Juan II, formando parejas con ellos en materia canónica y secular respectivamente. Esa intención de distinguir materias estaba implícita en la ley de 1427, pero no cabe duda de una mucho mejor forma de presentarla en el precepto de su hija. Con todo, lo más significativo es la exclusión de autores que no sean los cuatro citados, mientras que con la ley del padre cabía la posibilidad de alegar argumentos y fundamentar sentencias con cualesquiera de los criterios esgrimidos por los juristas anteriores a Juan Andrés y a Bartolo, como la poesía antes comentada muestra que sucedía.

Prueba del realismo que distinguía a los comisionados es la decisión de introducir (Ordenanza 14) los criterios de improrrogabilidad y perentoriedad para cualquier plazo procesal, eliminando las posibilidades flexibilizadoras de los jueces, que venían usando de ellas con poca honestidad en general, según el criterio más frecuente.

De la primera regla hay que decir que tuvo la sola excepción de los testigos que estuviesen «allende la mar» que disponen de seis meses para acudir como tales. El tribunal podría abreviar los plazos, pero nunca alargarlos.

De la segunda resulta que todos los plazos son perentorios, como se repite una y otra vez, es decir, que tienen efectos automáticos. Esas normas estarán, desde el momento de la iniciación, informando todas las actuaciones del proceso.

Por fin, además de ese realismo, las Leyes procesales isabelinas tuvieron una intención expresa de universalidad, al pretender abarcar todas las instancias, e incluso los arbitrajes (Ordenanza 43). La lectura de 
las Leyes revela sobre todo la existencia de un núcleo especialmente cuidado en la regulación de la primera inatancia, que corre desde la iniciación del juicio, hasta resolver la cuestión de las excepciones. Se creyó sin duda que, encarrilado así todo proceso, bastaría luego hacer referencias más particularizadas a varios de los desarrollos posibles en momentos concretos de las sucesivas instancias.

\section{El dibujo del proceso}

Me atrevo a pedir al lector que siga conmigo ahora las líneas maestras del dibujo procesal que trazaron los comisionados. Merece la pena.

El perfil que determina ese dibujo es la regulación de la primera instancia, ya que si se conseguía trazarla superando los embarramientos introducidos por las prácticas que ya conocemos, se disponía de una pauta esencial de comportamiento, que luego bastaría adaptar, que no calcar, en las instancias sucesivas. Dicho de otro modo, la suerte entera de la reforma se jugaba en lograr sanear con éxito la primera instancia.

Para conseguirlo se contempla inicialmente la intención formalizada de iniciar el proceso (mover pleyto) por alguna de las partes, a la que conforme a la tradición romana se sigue llamando actor. Este, antes de recibir la confirmación (carta de emplazamiento) de que se admitía a trámite su petición, debía acreditar los fundamentos de la pretensión esgrimida, por medio de documentos fidedignos o en su lugar por el juramento de tener testigos de tales fundamentos. También debía entonces designar procurador con poder bastante para las actuaciones que tendrían lugar después. Paralelamente se recortaba la posibilidad de discrecionalidad judicial en los plazos de citación al demandado (emplazamientos).

Se acotaba con esas medidas el marco de los movimientos posteriores del actor, ya que no se le admitiría la introducción posterior de la documentación que no hubiese presentado en la iniciación. Además, la presencia del auxilio técnico que radicaba en el procurador, daba seguridad a los jueces respecto de lo ajustado a Derecho de los actos de quien le nombraba.

De esa forma ya desde el comienzo se eliminaban formalidades dilatorias, como venían siendo el requisito de exigir al actor el trámite de la denuncia formal de la incomparecencia o rebeldía del demandado, para que ésta fuese estimada por los jueces. Es de advertir, por otro lado que, 
coherentemente, se cercenan drásticamente los usos judiciales que tendían a alargar los treinta o cuarenta días que correspondía observar, para citar al demandado.

En esos planteamientos discurren las tres primeras Ordenanzas, descubriéndose con ello la voluntad de extirpar tanto las maniobras ajenas a la buena fe por parte de los pleiteantes, como la excesiva libertada estimatoria de los jueces, que era la cobertura de las decisiones movidas por cohechos o desidias.

Esa misma intención de «brevedad y orden» que no en vano invoca la titulación con la que estas Ordenanzas fueron impresas, se sigue manifestando cuando, a renglón seguido, se reconoce al actor (Ordenanza 4) la posibilidad de elegir entre acogerse al derecho de asentamiento, o continuar el pleito para obtener una sentencia fundada en pruebas. Consistía el primero, según muestra el tablero normativo-doctrinal integrado por las Flores de las leyes $(1,12)$, el Doctrinal $(2,4)$, las Siete Partidas $(3,8,1)$, el Ordenamiento de Alcalá $(6,1)$ y el Ordenamiento de Montalvo $(3,9,1)$ en conceder al actor la posesión de los bienes por los que pleiteaba, si el demandado no accedía comparecer en el juicio al que había sido emplazado.

La diferencia entre ese conjunto y las Leyes de 1499 consistía en que, en éstas, se diseñaba de forma mucho más breve y automática que en aquel. Una vez más se advierte que no se trataba tanto de introducir un proceso distinto, cuando de limpiar el ya existente de los recovecos que había ido creando una ganga de arbitrariedades judiciales y de marrullerías de los letrados informantes.

Los comisionados redactores de las Leyes de los Católicos aportan un ejemplo de esas viciosas prácticas en la siguiente de sus Ordenanzas, cuando describen cómo los "parientes y administradores» de menores involucrados en alguna reclamación, de capital o de gestión, "por malicia y por dilatar el pleyto el menor reo se absenta o se esconde o le esconden». Nos están hablando de patrimonios de menores, administrados en perjuicio de éstos, y de los que tales agentes, supuestamente tutelares, ni ser quieren desprovistos de tales bienes, ni admiten ser examinados en sus conductas, supuestamente tuitivas.

Presente el demandado, se le aplica la misma cautela de actuar por procurador, como se había exigido al actor (Ordenanza 6) y después ambos, demandado y demandante, son sometidos un régimen idéntico de control judicial, para que no puedan en ningún momento alterar, falsificar, ni 
hacer extraviar las pruebas documentales que inicialmente habían exhibido, tanto para iniciar el juicio como para fundamentar su oposición.

Gráficamente se extiende la Ordenanza 7 en un complejo reglamento de esa custodia judicial de los originales presentados, que no es necesario reproducir aquí, donde bastará recoger la sobria crudeza con la que los redactores de las Leyes abreviadoras y ordenadoras declaran que, por no existir hasta entonces esas cautelas, estaba a la orden del día la más desatada corrupción en las oficinas y funcionarios judiciales, en beneficio suyo y de los litigantes felones, pero en perjuicio de los honrados:

«la esperiencia a mostrado que se han fengidamente [vuelto a redactar] las escrituras perdidas y se han anulado los processos e alas partes han recrecido otros daños e perdidas e grandes costas»

Asegurado todo lo anterior, el juicio habría iniciado una andadura equitativa y fiable, pero ahora debía cruzar uno de sus más profundos pantanos. Había llegado la hora de formular las llamadas excepciones.

Ya sabemos que reinaba una sorda exasperación social ante el abuso de de esas fórmulas, lo cual es fácil de entender si se piensa que, aún siendo fruto de la inteligencia la mayoría de ellas, eso no les daba respetabilidad. Y no es de despreciar el dato de que sus discursos al respecto se presentasen soportados en un amplio repertorio de reglas y citas en latín en el seno de una sociedad ampliamente analfabeta. Las gentes no las veían como fruto de una sincera profundización en los supuestos, buscando aquilatarlos honradamente, sino como sutiles recovecos que burlaban el sentido de la justicia. Además eran mucho más patentes que las sórdidas maniobras de falsificación y supuesta pérdida de pruebas documentales urdidas en las covachuelas de los juzgados mediante secretos sobornos.

Esas últimas infamias, por grandes que fuesen en sí mismas, solo en contados casos alcanzabañ difusión social, pero las excepciones constituían el gran nudo público y conocido de los discursos procesales. Basta leer el desarrollo de las excepciones en la parodia de juicio referido a unos animales que traza el Arcipreste de Hita en el pasaje de su Libro del buen amor titulado: Aquí fabla del pleito qu'el lobo e la raposa ovieron ante don Ximio, alcalde de Bugia, para comprender que la mayor carga del rechazo social que recaía sobre los juicios, se centraba en dos ejes, el engañoso juego de las excepciones, anulando o dilatando el proceso iniciado y en la desatada venalidad de los jueces.

El camino que se ofrecía a los comisionados era estrecho. Tendrían que operar de nuevo sobre tres factores: el tiempo concedido para la pre- 
sentación; la nitidez, concisión y prueba de la argumentación exhibida; y la sentencia que pone fin al edificio de las excepciones, cuya presencia en sí misma no se discute.

De las dos primeras cosas se ocuparon las Ordenanzas 8 y 10, donde se preceptúa un espacio temporal que, sumando plazos internos, alcanza a los veintinueve días. En ellas se albergan dos periodos, nueve días desde el emplazamiento para plantear la excepción y veinte para discutirla y en su caso probarla.

En todo momento se dibuja con gran agilidad el espacio de actuación que ciñe a las partes, atendiendo sobre todo a lograr claridad, certeza, rapidez en la disponibilidad y conocimiento recíproco de las documentaciones y soportes argumentales presentados en apoyo de lo pretendido con la excepción. A su vez la Ordenanza 9 dará una resolución final al incidente, ordenando que de la decisión judicial que lo zanja (llamada también sentencia):

«no haya lugar $[a]$ suplicación [es decir, apelación] ni nulidad, ni otro remedio ninguno».

Una nueva finta podría plantearse llegado ese momento del pleito, la reconvención del demandado al actor, cosa que en fin de cuentas, no era sino acusarle de haber cometido alguna acción análoga a aquella contra la que demandaba. De nuevo se acude a la limitación temporal rígida como medio de evitar que suponga una maniobra dilatoria. La Ordenan$z a 11$ establece para toda esa discusión un periodo total de diecisiete días a contar de la comunicación de la reconvención al actor:

$« y$ dende en adelante no se reciban otras peticiones ni replicaciones y con esto se haya

la causa [de la reconvención] por conclusa, sin otro auto de conclusión»

El nudo central del proceso, que se abría a continuación, está regulado por la Ordenanza 11, que constituye el corazón de la reforma. Se refiere al momento en que, superados los escollos anteriores, las partes fijaban sus respectivas pretensiones (posiciones) es decir los motivos y cuestiones para cuya resolución habían acudido al juicio, y procedían a lo que se sigue llamando, de acuerdo con la tradición, juramento de calumnia.

Sabemos que éste (convertido en un tópico de la práctica forense que las Leyes de Madrid, no consideraron necesario explicar) consistía en jurasen las partes que: pedían lo que se creían ser justo; dirían la verdad en lo que se supiere y les fuere preguntado; no habían introducido sobornos, sino el pago adecuado de los honorarios exactos; no aportarían en 
ningún momento pruebas falsas; no solicitarían plazos con la única intención de alargar el pleito (Flores de las Leyes, 2,3,1).

En la práctica este momento de la fijación de posiciones era también utilizado, como se desprende de la misma Ordenanza 11, para volver a las disimulaciones y engaños recíprocos, mediante la técnica del embarullamiento. Se solían mezclar posiciones con excepciones o reconvenciones. También era frecuente acudir a la fórmula de respuestas vagas, respondiendo al contrario, «creo» o «no creo». O se intentaba trasladar la inseguridad acerca de lo que se estaba discutiendo y para ello se negaba, no lo que se discutía, sino la forma en que el otro planteaba su pretensión, respondiéndole que el desacuerdo se reducía a «tal como en ella [es decir la posición que había manifestado ante el tribunal] se contiene» o «según la ponen», sus letrados, etc.

Pero como ya la legislación isabelina daba a los jueces el arma para evitar esas argucias, separando como se ha visto, el tratamiento y resolución de las excepciones y reconvenciones, basta ahora con que esa Ordenanza 11 imponga unas pautas de respuestas concretas, no escurridizas ni ambiguas, que debían exigirse por los mismos jueces a los litigantes, para que resultase nítido aquello por lo que habían acudido al Tribunal. Además se impone a éste (Ordenanzas 12 y 13) el cuidado en vigilar que existiese igualdad de oportunidades entre actor y demandado para esta fijación de posiciones.

Fundamental es también lo dispuesto en la misma Ordenanza 11, sobre cómo debe recibir, el órgano que juzga, esas posiciones de los litigantes para su conocimiento y prueba. Como lo esencial de ese paso era que las pruebas que hubiesen de practicarse a continuación tuviesen ya un marco definido que delimitaba su significación, procedía entonces repartirlas recíprocamente entre los litigantes, si se ajustaban a lo mandado en la Ordenanza 13. No se permitía a los letrados repreguntar cuando se hubiese producido confesión de parte y se fijaban una serie de plazos para aportar los testigos que a cada litigante convinieren.

Hecho todo eso, habría por lo regular, junto a las posiciones confesadas, sobre las que no se podía volver, como hemos visto, otras posiciones negadas acerca de las cuales era necesario su esclarecimiento mediante pruebas. Debían ahora (Ordenanza 14) los jueces ordenar la práctica de éstas, dentro de los criterios que ya conocemos acerca de los plazos. De regular la prueba testifical se ocupó la Ordenanza 15, indagando presio- 
nes, vínculos, corrupciones, etc., de los citados como testigos, para cuya tacha se da un plazo de seis días (Ordenanza 15).

Las posibilidades de recusar a uno o varios de los jueces, desaparecen cuando ya se ha dado la causa como vista para sentencia (Ordenanza 20) y dictada ésta se abre un plazo de diez días para recurrir de ella (Ordenanza 21).

Las Leyes matritenses nos relatan, como propia de estas alturas del proceso, una «malicia» practicada por medio de «sobornación de testigos o corrución». Se trataba de la «restitución», figura jurídica procedente de la teoría romana de la restitutio in integrum que, si se aplicaba a supuestos muy diferentes entre sí, consistía en fin de cuentas en una decisión judicial por la que negaba toda validez a una determinada situación, volviendo las cosas al estado en que se encontraban antes de que aquélla se produjese. En el terreno al que se refieren las Leyes de 1499, consistía simplemente en que, cuando ya se conocían todas las cartas de la parte contraria, se urdía una serie de pruebas falsas, para dejar las posiciones de ella sin fundamentos jurídicos $\mathrm{y}$, alegando que esas pruebas no se habían podido presentar antes, porque no se conocían, se solicitaba la nulidad de actuaciones.

Para «oviar a la malicia», se dispusieron una serie de cautelas y estrechamientos de maniobra (Ordenanzas 17 y 18), otorgando la posibilidad recíproca a la parte contraria; admitiéndola a quien la solicite, si es sujeto protegido por un régimen de Derecho privilegiado para pedirla, pero en un plazo calculado para que no pueda conocer la totalidad de la argumentación esgrimida por el contrario, y sometiendo al peticionario a un régimen de fianzas, mas garantías de no reiniciar esa petición.

Con intención análoga se trataron otras dos armas susceptibles también de usos poco limpios; las recusaciones al Tribunal o a sus miembros aisladamente (Ordenanzas 19 y 20); y los recursos (suplicaciones) presentados a decisiones del órgano jurisdiccional en puntos del proceso que no afectaban a la resolución del tema ventilado en el pleito (cuestiones interlocutorias), pero en las que se podían introducir enzarzamientos rebuscadamente orientados a retrasar el proceso (Ordenanza 21).

Largo y engorroso quizá le haya parecido al lector el camino recorrido hasta ahora, pero por grande que sea su aburrimiento le habrán resultado también patentes dos cosas esenciales: lo envenenado del ambiente y lo minucioso del examen corrector emprendido por decisión de la reina Isabel. Solo habría que añadir cómo esa benéfica minucia se reem- 
prende enseguida, a partir de la Ordenanza 22, cuando se abren las posibilidades de nuevas instancias y de procesos especiales, de las que basta decir aquí que se examinan con prolijidad similar e idéntico espíritu de saneamiento.

\section{Destino y sentido del intento}

La reforma procesal de Isabel la Católica, fue la primera en magnitud emprendida en sus reinos. Aunque puedan espigarse puntos concretos de coincidencia (tampoco demasiados) en la legislación territorial anterior a ella, es evidente que no existe una ley semejante en la materia, ni por lo monográfico del tema ni por la universalidad de las aspectos abordados.

No solo fue la primera. Fue también la única durante siglos. Recogidos casi literalmente sus preceptos en la Recopilación de Felipe II en 1567, ya se han indicado los caminos por los que llegó intacta hasta principios de siglo XIX y de forma muy importante perduró aún en los textos que en la segunda mitad de ese siglo empezaron a sustituirla.

$\mathrm{Su}$ presencia se trasladó al mundo americano de habla española, a través de los juristas que, doctrinal o judicialmente, ejercieron allí sus tareas y las previsiones contenidas en su Ordenanza 37, fueron el cauce por el cual la doctrina jurídica europea del ius commune, especialmente la debida a los doctores italianos, se integró en la Ciuitas iuris atlántica edificada por España sobre el soporte de los Continentes a los que extendió su hegemonía de gobernación y justicia.

Que hubo juristas y jueces empeñados en burlar la intención de transparencia y honestidad perseguida por las Leyes de Madrid, es sin duda alguna cierto. Pero no lo es menos que también los hubo y no dejan de aparecer especialmente en los legajos de los Archivos conservados en diversas repúblicas de Hispanoamérica, quienes empeñaron todos los esfuerzos que les fueron accesibles para dignificar la asistencia letrada y la administración de justicia.

Sería desde luego una exageración pensar que la máxima del Salmo 84, «Iustitia de caelo prospexit», con la que gustaban de engalanar las ediciones del Corpus iuris ciuilis los encuadernadores del siglo XVIII, pudiese resumir la abigarrada y poco gloriosa historia del enjuiciamiento. Pero nadie puede negar a esta Reina, mestiza de Castilla y Portugal, el valor de llamar a quienes podían ayudar mucho en la corrección de abusos y el de promulgar luego el resultado de sus dictámenes 